DOE/PC/95231-26

DIST. CATEGORY UC-112

UTSI-99-07

\title{
TECHNICAL PROGRESS REPORT FOR \\ UTSI/CFFF MHD PROGRAM COMPLETION AND RELATED ACTIVITY
}

For The Period

July 1, 1999 - September 30, 1999

October 1999

Work Performed Under Contract No. DE-AC22-95PC95231--29

Prepared for:

The United States Department of Energy

Prepared by

The University of Tennessee

Space Institute

Energy Conversion Research and Development Programs 


\section{DISCLAIMER}

This report was prepared as an account of work sponsored by an agency of the United States Government. Neither the United States Government, nor any agency thereof, nor any of their employees, makes any warranty, express or implied, or assumes any legal liability or responsibility for the accuracy, completeness, or usefulness of any information, apparatus, product, or process disclosed, or represents that its use would not infringe privately owned rights. Reference herein to any specific commercial product, process, or service by trade name, trademark, manufacturer, or otherwise does not necessarily constitute or imply its endorsement, recommendation, or favoring by the United States Government or any agency thereof. The views and opinions of authors expressed herein do not necessarily state or reflect those of the United States Government or any agency thereof. 


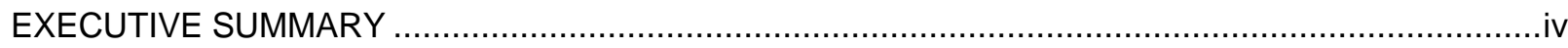

TASK 1 - FACILITY MAINTENANCE AND PROPERTY MANAGEMENT ..................................... 1

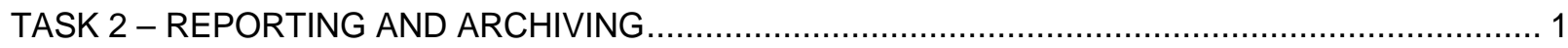

TASK 3 - SITE ENVIRONMENTAL COMPLIANCE AND REMEDIATION ..................................... 1

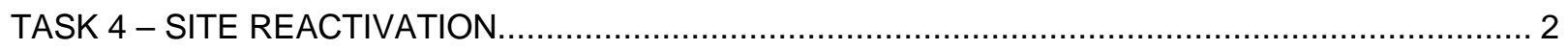

TASK 5 - DISASSEMBLY AND DISMANTLEMENT (D\&D) OF THE CFFF .................................. 2

TASK 6 - ADVANCED TECHNOLOGY, RESEARCH, DEVELOPMENT AND ENGINEERING FOR OTHER FEDERAL OR DOE PROGRAMS ........................................................ 2

Subtask 6.02 - Evaluation of Methods for Application of Epitaxial Buffer and Superconductor Layers.... 2

Subtask 6.03 - Coated Conductor Development and Program Management...................................... 4

Subtask 6.04 - Optimum Coated Conductor …............................................................. 5

Subtask 6.05 - Cost/Performance Analyses of Potential Manufacturing Processes ............................ 6

Subtask 6.06 - Development of Real Time Process Control Using In-Situ Diagnostics ....................... 6

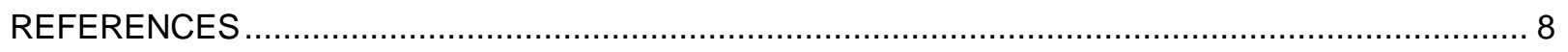

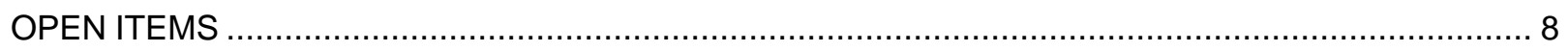

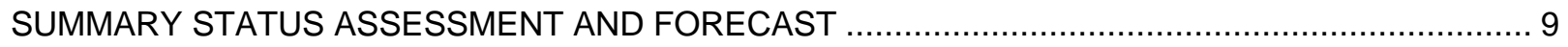

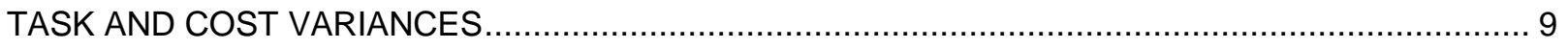

JULY 1, 1999 - SEPTEMBER 30, 1999 QUARTERLY VARIANCE REPORT ............................... 10 


\section{LIST OF FIGURES}

Page

Figure 6.02-1 $\mathrm{LaAlO}_{3}$ (111) Pole Figure of a Typical NiO/Ni Sample with a $\mathrm{La} \mathrm{AlO}_{3}$ Coating on a Top. No 45 In-Plane Rotated Component Exist............................................................................... 3

Figure 6.06-1 Measured Roughness of Plastronic B Annealed Nickel ......................................... 7

Figure 6.06-2 Quartz Cell and Oven Window Absorbance Spectra, 200-400 nm.............................. 7 


\section{LIST OF TABLES}

Page

Table 6.02-1 Sol-gel $\mathrm{LaA} 1 \mathrm{O}_{3}$ Films Applied on Cube Textured NiO on Nickel .9 


\section{EXECUTIVE SUMMARY}

Maintenance work on the DOE CFFF facility and other related government property remained in suspension in accordance with the stop work order issued by DOE. Environmental remediation preservation of the facility continued. Final actions were completed to dispose of the soil that was contaminated by diesel oil. Actions are underway to dispose of other wastes.

Progress is reported on the five (5) high temperature superconductivity projects under Task 6. Results are reported for various techniques for annealing cold rolled nickel tapes and applying buffer layer by the Sol-Gel process. Included in the annealing/coating work is one case that involved oxidizing the nickel to nickel oxide which is textured before application of the buffer layer. Work under the Optimum Coated Conductor included issuing a topical report describing the work on grain boundary grooving in nickel substrates as a function of annealing temperature and time. Also, the work to evaluate the mutual effects of adjacent superconductors. In the cost/performance analysis project, completion of a study on the economics of production of coated conductors by the MOCVD process is reported. In the diagnostics for real time process control project, a topical report that outlines the requirements for control of promising manufacturing processes was submitted, additional work is reported on using absorption spectroscopy as the basis for control of the stoichiometry for the MOCVD process and the work on scatterometry for measuring uniformity of surfaces is summarized. 


\section{TASK 1 - FACILITY MAINTENANCE AND PROPERTY MANAGEMENT}

In September 1998, a stop-work order was issued for work activity in the Doe Facility maintenance area. Work to administer government-owned property continued.

On September 22, 1999, Department of Energy and the University of Tennessee signed a SETTLEMENT AGREEMENT resolving all claims and property accountable under Tasks 1-5.

\section{TASK 2 - REPORTING AND ARCHIVING}

July, August and September Monthly Reports were submitted.

The following draft Topical Reports were submitted to DOE for approval:

"Experimental Study of the Effects of Annealing Time, Equilibrium Angle and Absolute Misorientation Angle on Thermal Grain-Boundary Grooving in Cube-Textured Nickel" - C. J. Simon (DOE/PC/95231-27).

"Life Cycle Cost Study for Coated Conductor Manufacture by Metal Organic Chemical Vapor Deposition"-J. N. Chapman (DOE/PC/95231-26).

The following draft Topical Report was approved with revisions and distributed:

"Development of In-Situ Control Diagnostics for Application of Epitaxial Superconductor and Buffer Layers", B. Winkleman, T. V. Giel, J. Cunningham (DOE/PC/95231-24).

The June Monthly Contract Status Report was submitted July 20, 1999.

The Quarterly Key Staffing Report for the period April - June 1999 was submitted July 20, 1999.

The Quarterly Technical Progress Report for the period April - June 1999 was submitted July 30, 1999.

The Draft Topical Report entitled "Experimental Study of the Effect of Annealing Time, Equilibrium Angle, and Absolute Misorientation Angle on Thermal Grain - Boundary Grooving in Cube Textured Nickel" was sent in electronic format to AA Document Control on August 11, 1999. It had previously been sent in hard copy format for review.

\section{TASK 3 - SITE ENVIRONMENTAL COMPLIANCE AND REMEDIATION}

UTSI shall continue implementation and compliance with the State of Tennessee approved plan for groundwater remediation. UTSI shall remove from the site, and properly dispose of, all industrial type non-hazardous wastes. In addition, UTSI shall properly remove all asbestoscontaining cooling water tower materials and dispose of these materials properly. In addition, UTSI shall continue the monitoring and treatment of holding pond effluent per the site Water Discharge Permit with the State of Tennessee.

The soil that was contaminated by diesel was successfully transported to and disposed of in the BFI Middle Point Landfill in Murfreesboro, TN.

The water monitoring and sampling required by the NPDES permit was completed. This includes weekly monitoring for $\mathrm{pH}$, flow and temperature and bimonthly monitoring for solids and oil and grease analysis. The monthly water report was completed and sent to the State as required. Sampling of the groundwater wells is scheduled for August. 
Disposition options for the remaining coal pile (estimated at 200 Tons of Montana Rosebud) is being investigated.

Oil and ash wastes on-site are being managed until permanent disposition can be negotiated. Mr. Rick Price, FETC Property Administrator for this contract, visited UTSI during June and promised assistance on resolving the transfer of the remaining seventeen (17) TRW tote bins that are filled with spend potassium seed and ash.

Four NPDES effluent monitoring episodes for $\mathrm{pH}$, flow, and temperature were completed. Two NPDES analyses were completed for suspended solids, dissolved solids and extraction for oil and grease.

A notice of violation was received for February 1999 for elevated oil and grease in NPDES report and for reporting oversight (left a block blank on the report form inadvertently).

Completed four NPDES effluent monitoring episodes for $\mathrm{pH}$, flow, and temperature.

Completed two NPDES analyses for suspended solids, dissolved solids and extraction for oil and grease.

Completed and sent required monthly discharge monitoring reports to State. No permit limits were exceeded.

Visited on September 14, 1999 by State representatives to review status of groundwater program. The representatives, Mr. Bryan Gant and Ashley Holt State Solid Waste Remediation Program, sent a letter after the visit directing UTSI to take action beyond the prior formal agreement. Management will discuss appropriate action and follow-up accordingly.

Received "abandon in place" letter from Rick Price (DOE/FETC) the seventeen (17) remaining tote bins. Basically, this authorizes UTSI to dispose of these items. Since that time UTSI has been given ownership of all DOE property on-site. The tote bins will be disposed of as a portion of the overall waste/restoration effort.

\section{TASK 4 - SITE REACTIVATION}

No work was scheduled or performed

\section{TASK 5 - DISASSEMBLY AND DISMANTLEMENT (D\&D) OF THE CFFF}

No work was scheduled or performed

\section{TASK 6 - ADVANCED TECHNOLOGY, RESEARACH, DEVELOPMENT AND ENGINERING FOR OTHER FEDERAL OR DOE PROGRAMS}

\section{Subtask 6.02 Evaluation of Methods for Application of Epitaxial Buffer and Superconductor} Layers

The annealing study that was conducted to evaluate grain boundary angles and twining fraction as a function of annealing time for nickel was summarized in the DOE Peer Review in Washington.

During July we experimented with changing the processing temperature of sol-gel depositing $\mathrm{LaAlO}_{3}$ films on nickel tapes having a cube textured $\mathrm{NiO}$ layer on the surface. As may be seen from Table 6.02-1, varying the processing temperature between 950 and $1150^{\circ} \mathrm{C}$ resulted in no discernable effect on $\mathrm{LaAlO}_{3}$ epitaxial growth as determined by phase, omega, and phi x-ray diffraction scans. In contrast to the case of $\mathrm{LaAlO}_{3}$ on nickel, no in-plane $45^{\circ}$ rotated texture 
component occurred for $\mathrm{LaAlO}_{3}$ on $\mathrm{NiO}$ at any temperature. While $\mathrm{NiO}$ layers were retained after processing samples at or below $1050^{\circ} \mathrm{C}$, the $\mathrm{NiO}$ was removed at higher temperatures. The positions of $\mathrm{NiO}$ peaks in $\mathrm{x}$-ray phase scans were sharply shifted to larger d-spacing, indicating the likelihood that lanthanum and/or aluminum had dissolved into it.

An attempt at improving $\mathrm{LaAlO}_{3}$ crystallization and epitaxy on $\mathrm{NiO}$ coated samples by addition of a small amount of $\mathrm{O}_{2}$ to the atmosphere during thermal processing was unsuccessful, resulting in thickening of the NiO layer and a virtual absence of $\mathrm{LaAlO}_{3}$. The amount of oxygen used was around $0.5 \%$ by volume of the argon flow rate.

An attempt was made at preparing a sol-gel precursor solution for $\mathrm{YAlO}_{3}$, using 2-methoxyethanol as the solvent and performing ligand exchanges with both $\mathrm{Al}$ and $\mathrm{Y}$, in the manner used for

Table 6.02-1. Sol-gel $\mathrm{LaAlO}_{3}$ Films Applied on Cube Textured NiO on Nickel

$\begin{array}{cccccc}\text { Sample } & \begin{array}{c}\text { Thermal } \\ \text { Processing } \\ \text { Temp., }{ }^{\circ} \mathrm{C}\end{array} & \begin{array}{c}\mathrm{LaAlO}_{3}(100) /(100)+(110)+(111) \\ \text { Phase Scan Peak Height }\end{array} & \begin{array}{c}\mathrm{LaAlO}_{3} \\ (111) \mathrm{Phi} \\ \mathrm{FWHM}\end{array} & \begin{array}{c}\% \text { of In- } \\ \text { plane 45 } \\ \text { Rotation }\end{array} & \begin{array}{c}\mathrm{LaAlO}_{3}(200) \\ \mathrm{RD} \text { Omega } \\ \text { FWHM }\end{array} \\ \mathrm{K} 27 & 950 & 0.46 & 13.94 & 0 & 18.06 \\ \mathrm{~K} 29 & 950 & 0.76 & 12.81 & 0 & 16.18 \\ \mathrm{~K} 30 & 950 & 0.70 & 12.35 & 0 & 16.34 \\ \mathrm{~K} 28 & 989 & 0.40 & 17.82 & 0 & 28.93 \\ \mathrm{~K} 24 & 1050 & & 11.12 & 0 & 17.21 \\ \mathrm{~K} 31 & 1050 & 0.63 & 16.94 & 0 & 24.58 \\ \mathrm{~K} 32 & 1050 & 0.65 & 16.33 & 0 & 21.23 \\ \mathrm{~K} 16 & 1150 & 0.76 & 11.33 & 0 & 15.99 \\ \mathrm{~K} 17 & 1150 & 0.76 & 12.89 & 0 & 17.26 \\ & & & \text { Avg. } 13.95 & & \text { Avg. } 19.53\end{array}$

preparing the $\mathrm{LaAlO}_{3}$ precursor. However, a lack of solubility of yttrium isopropoxide was encountered, owing either to it being inherently not very soluble in 2-methoxyethanol, to being contaminated with atmospheric moisture, or to failing to exchange ligands (isopropoxy for 2methoxyethoxy). Whichever the case, we reordered and have received new batches of yttrium isopropoxide and 2-propanol.

As a result of devitrification of quartz thermal processing tubes at the $1150^{\circ} \mathrm{C}$ temperature normally used, a mullite tube was obtained and minor modifications are underway to permit its substitution for the quartz.

Conclusion: No trends are evident.

Note: Samples processed above $1150^{\circ} \mathrm{C}$ lost all $\mathrm{NiO}$, those below retained $\mathrm{NiO}$.

Familiarity was gained in using an optical profilometer to measure the surface roughness of nickel samples. It was found, however, that this optical profilometer had insufficient resolution for our purpose, which was to determine the surface roughness of the interior of grains before and after electropolishing. The optical profilometer scanned an area of $1.8 \mathrm{~mm} \times 2.4 \mathrm{~mm}$ producing $256 \times 256$ pixels of data. This area included many different grains and their boundary grooves. It appeared that the surface roughness measurements that the machine recorded were mainly a function of the difference between the grooves and the grain surface. The magnitude of the difference was on the order of 1 to 3 microns. 
The problem with this was that electropolishing of nickel samples probably took peaks off the grain surface on the order of nanometers. No improvements in the grain surface could be measured because the amount removed was insignificant relative to the difference between the surface and the boundary grooves.

Even if the groove portion of the data were excluded by an image processing procedure, it is doubtful that the machine collected enough pixels on each grain to accurately calculate the roughness of the grain interior surface alone. Oak Ridge used an AFM machine that had high enough resolution to examine areas of 1 square micron, and their findings showed Ra values of 4-5 nm, which the optical profilometer probably isn't sensitive enough to detect.

However, the optical profilometer could reveal differences in surface roughness due to varying nickel annealing conditions. Nickel that was annealed for short times, $1 \mathrm{hr}$ or so, had indicated $\mathrm{Ra}$ values between 1-1.5 microns, while samples annealed for long times, such as $20 \mathrm{hrs}$, had indicated $\mathrm{Ra}$ values of 2-3 microns. This was due to the deepening of grain boundary grooves with longer anneal times.

The merit of the optical profilometer equipment is that we can roughly quantify the severity of grain boundary grooving. The drawback is that we can't isolate grain interior surface roughness as a separate factor to be manipulated with polishing techniques.

Some of the welded joints on the diffusion pump used in the annealing rig came loose. As a result, the rig pressure could not be brought down to the normal operating condition of $10^{-6}$ torr. The required parts of the pump are on order and expected to arrive in the middle of October 1999.

In the meantime, experiments were carried out to test the feasibility of eliminating the heat treatment step. There are two major advantages possible if this step can be avoided. One, the non-annealed nickel would remain hard and easy to work with. Second, the surface roughness of the untreated nickel can then be measured using the optical profilometer. According to previous work at UTSI, it was found that the best textures for nickel samples occur with some heat treatment at very high temperatures and for time exceeding 20 hours. However, from our recent experiments, the untreated samples produced some (100) peaks that were fairly strong and these peaks were clearly more favored than the other orientations. However, a strange peak of nearly equal intensity as the (100) peak also showed up in the phase scan. Initially, we thought that it may be due to $\mathrm{LaO}$, but now it seems that the precursor solution of lanthanum aluminate may be the reason. In poorly developed precursor solution, mixed metal complex formation can be incomplete or lanthanum metal can be in excess or that the lanthanum iso-propoxide may be contaminated with water prior to reflux. To eliminate the last reason, the gloves to the nitrogenpurged glove box where the chemicals are stored has been changed and the box humidity level and the inert gas consumption, both have gone down significantly.

A 2-3 page, thesis proposal has been prepared which will be sent to UT Knoxville campus to identify possible MS-thesis committee members from the Chemical Engineering Department.

A table in the accepted and published technical paper entitled "Bench Scale Evaluation of Batch Mode Dip-Coating of Sol-Gel $\mathrm{LaAlO}_{3}$ Buffer Material" was corrected and the revised table was transmitted to the editor of the IEEE Transactions on Applied Superconductivity.

\section{Subtask 6.03 Coated Conductor Development and Program Management}

The major activities under this subtask this month was in preparation for and participation in the DOE Peer Review in Washington, and the termination of the high temperature super-conductivity program being carried out under Task 6 . The tentative plan is as follows: 
Continue Subtask 6.02 into FY2000 as funds remaining permit. Continue to support one Chemical Engineering Graduate Research Assistant to complete a Sol Gel report, which is to include the cost/performance analysis of the Sol Gel Process.

Continue Subtask 6.03 as funds permit.

Discontinue Subtask 6.04 effective September $30^{\text {th }}$.

Discontinue Subtask 6.05 effective August $31^{\text {st }}$. The remaining milestone to complete the cost/ performance study for the Sol Gel process will be completed under Subtask 6.02 as mentioned above.

Discontinue Subtask 6.06 effective September $30^{\text {th }}$. The two physics graduate research assistants assigned to this project will be reassigned to other UTSI programs.

\section{Subtask 6.04 Optimum Coated Conductor}

The topical report describing the parametric study of grain boundary grooving in cube-textured nickel as a function of annealing temperature and time was summarized very briefly in the UTSI presentation at the DOE Peer Review. It was covered in substantially more detail in the ORNL presentation.

Setting up the experiment to measure the coupling between adjacent parallel superconducting tapes continued. Mechanical clamping of the power leads (\#12 copper wire) is accomplished with cable clamps fastened to a phenolic sheet strip which acts as a base and support for the superconductor tape. Multiple holes in the phenolic permit the spacing between the conductors to be varied. This setup allows all of the connections to be made with the installation of the superconducting tapes being last to minimize their handling as they are quite flimsy compared with copper wire. Transparent tape will be used to insulate the tapes.

The experimental results sought are the V-I characteristics of each of the wires in their own self field. By varying the distance between the conductors, the coupling should also vary such that the total critical current is greatest when the conductors are furthest apart and essentially uncoupled. Essentially the experiment was to measure changes in the critical currents in 16 inch long conductors with increases in the separation distance between them. It is difficult to even maintain a fixed separation between two long wires in a liquid nitrogen bath let alone change their separation while they are in the liquid bath. As a consequence, the superconducting tape lengths were initially laid side by side on a glass epoxy board such that the separation between the was approximately one half of the tape width (about 1/16th inch). He board with the tapes attached was submerged in liquid nitrogen and, using a $1 \mu \mathrm{V} / \mathrm{cm}$ criteria, the critical currents in the two tapes were measured to be 6.35 and 5.10 Amperes. Since the tapes were connected electrically parallel when one of the tapes was at its critical current the other was either at a sub or supercritical current. It was noted that the currents in the two parallel circuit legs were quite evenly matched as a result of the legs having identical tape and lead lengths.

The tapes were subsequently removed from the glass epoxy board and reinstalled with a separation of approximately 5.5 tape widths (about $3 / 4$ inch). Repeating the measurement with the wider separation resulted in critical currents of approximately 5.9 and 4.65 Amperes, respectively. The reason for the lower values is unknown. However, it was noted that, in the case of the second measurement, the current was not as evenly matched between the two legs of the circuit with the leg having the apparently higher critical current tape carrying approximately $2 / 3$ of the total current over the full range of currents tested. This may suggest that an extraneous connection resistance was in some way influencing the measurement. 
Subtask 6.05 Cost Performance Analysis of Potential Manufacturing Processes

The cost/performance study for manufacture of YBCO superconducting wire by the MOCVD process was presented in summary form at the DOE Peer Review. The University of Houston made a presentation in which they outlined their plans for commercialization of this process by private companies. Their projected cost for production of the required precursors in-house was $\$ 500 / \mathrm{kg}$, half the base case number used in the study. However, they projected a lower material utilization efficiency, which make their cost of production similar to that derived in the base case of the study.

ORNL and others presented recent work on development of Sol-Gel manufacturing processes that included new possibilities for the buffer layer materials. Work during this period on the SolGel study has concentrated on exploring these additional architectures.

This subtask was terminated at the end of August as funds were depleted. The remaining work will be carried out in Subtask 6.02 .

\section{Subtask 6.06 Development of Real Time process Control using In-Situ Diagnostics}

Results of application of optical scatterometry technology to surface smoothness of superconductors and substrates were presented at the DOE Peer Review. Application of this technique for real time control of manufacturing processes was illustrated. Also, the results of the measurement of absorption data for MOCVD precursors for stoichiometric control of the deposition process was summarized.

\section{Surface Roughness System (Optical Scatterometry)}

Work continued on defining a system orientation for practical application of the technology to the manufacture of coated conductors. After the laser spot was refocused to a larger spot size $(7 \mathrm{~mm}$ long by $1.5 \mathrm{~mm}$ wide) a surface coverage rate of $0.35 \mathrm{~cm}^{2} / \mathrm{min}$ was achieved. Using a more rapid traverse system and the full capabilities of the Finish Measurement System, it is estimated that scans of at least $100 \mathrm{~cm}^{2} / \mathrm{sec}$ can be achieved. Although these scans would not provide twodimensional high-resolution measurements of the surface roughness as achieved with a $0.1 \mathrm{~mm}$ diameter spot size, the larger spot size scans would indicate quality problems in real time, as needed for process control.

Data reduction from high-resolution measurements of electropolished substrates continued. Unfortunately, a power outage interrupted this data reduction process, and data reduction has to be reinitiated. However, further work will be substantially curtailed due to non-availability of personnel.

\section{Absorption Spectroscopy of MOCVD Precursors}

Because ultraviolet (UV) spectral molar absorptivities acquired earlier on gas phase copper, yttrium, and barium THD MOCVD precursors were more than an order of magnitude less than previously published liquid phase absorptivities ${ }^{1,2}$, the previous liquid phase studies were simulated using our apparatus. Like these previous studies, absorbances were measured for the THD compounds solved in UV spectroscopic grade n-Hexane. (THD represents 2,2,6,6-tetramethyl-3,5-heptanedionato, as in $B a(T H D)_{2}$, and is also referred to as $D P M$ for dipivaloylmethane.) The resulting $\mathrm{Ba}(T H D)_{2}, \mathrm{Cu}(T H D)_{2}$ and $Y(T H D)_{3}$ liquid phase absorbance scans, presenting in Figures 6.06-1, 6.06-2 and 6.06-3, show the same absorbance peaks as the absorbance scans reported in the literature. Wavelength specific molar absorptivity values calculated from these scans also show agreement within the uncertainties of the measurements. 


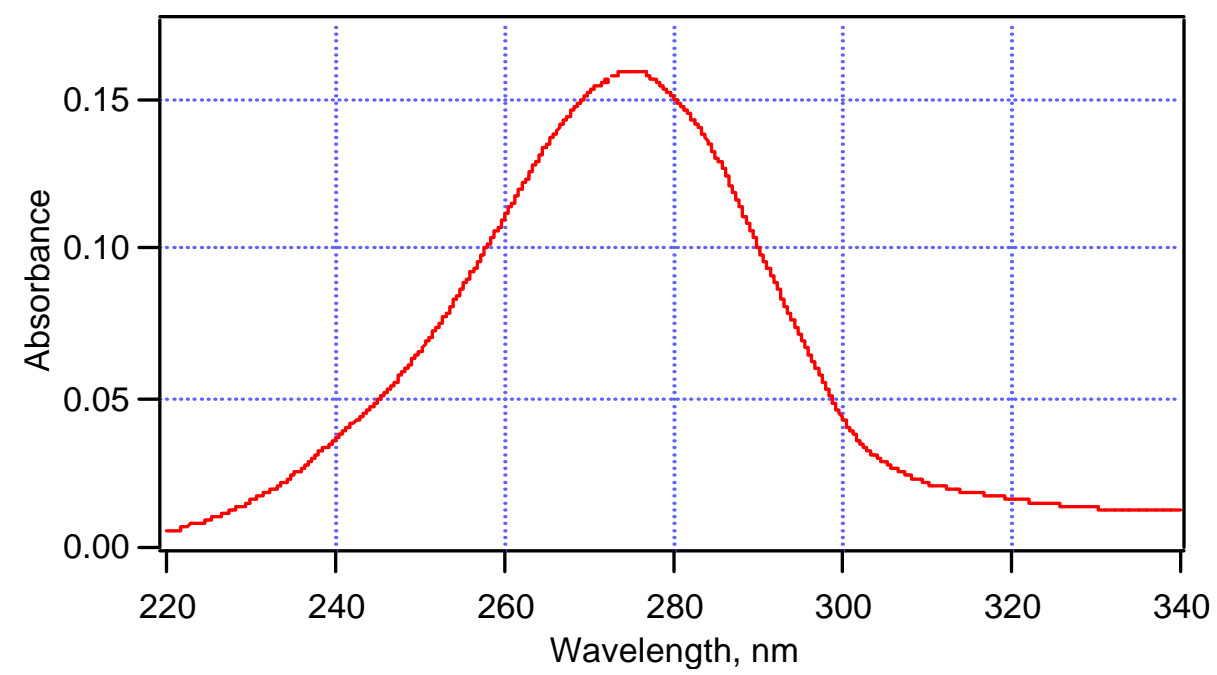

Figure 6.06-1 $\mathrm{Ba}(T H D)_{2}$ solved in n-Hexane Absorbance Scan

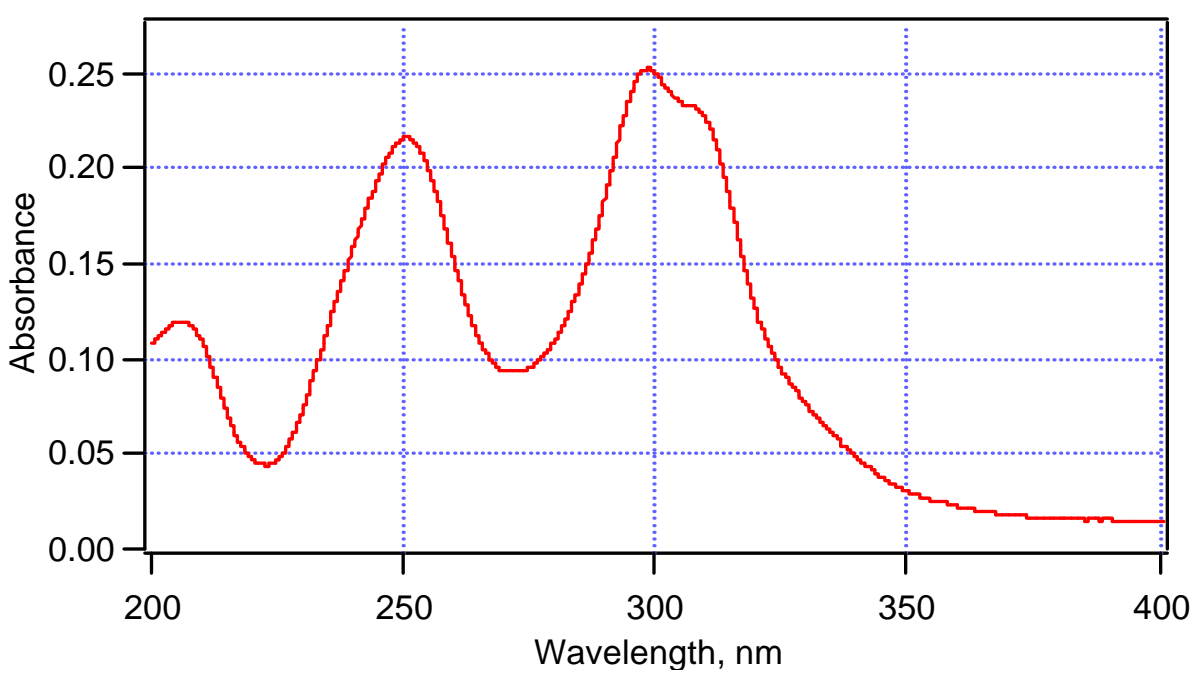

Figure 6.06-2 $\mathrm{Cu}(\mathrm{THD})_{2}$ solved in n-Hexane Absorbance Scan 


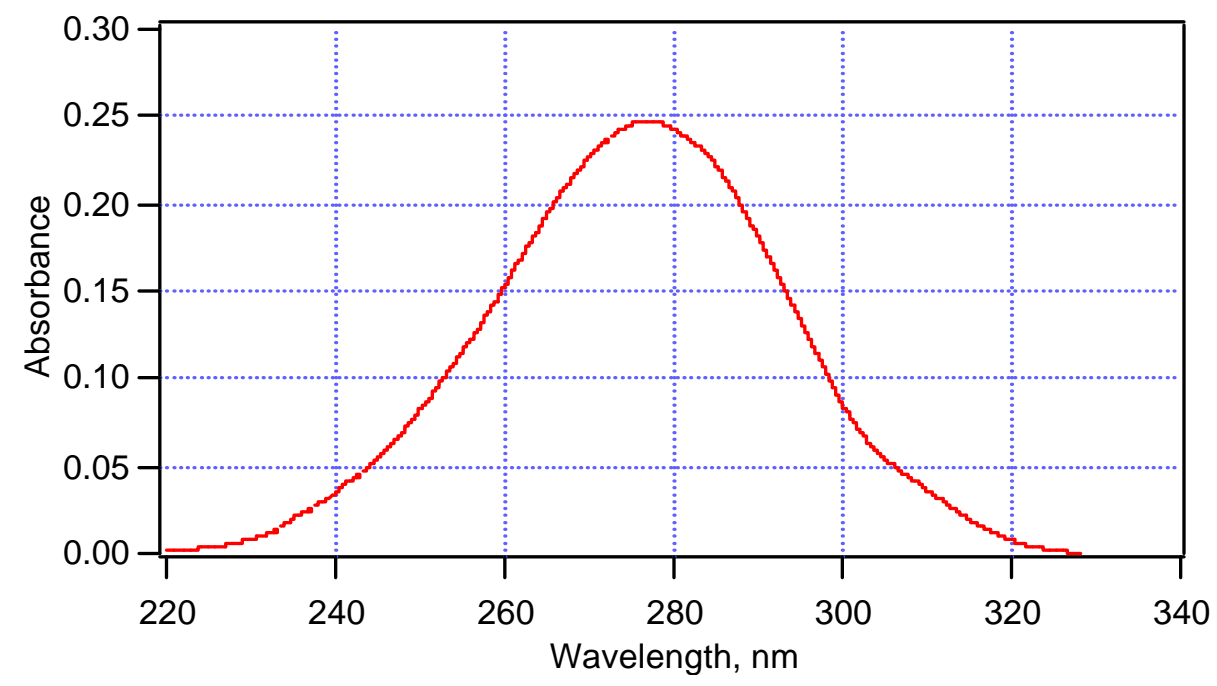

Figure 6.06-3 $Y(T H D)_{3}$ solved in n-Hexane Absorbance Scan

\section{Raman Spectroscopy}

Changed setup of experiment to utilize different collection angles other than back scattering. Collected spectra from sulfur samples and compared collected data with published results. Spectra collected in the laboratory were in agreement with those results.

Attempted again to collect spectra from YBCO samples, but was unable to detect Raman lines. This occurred using both the thin film sample and the YBCO that was made in house. Plans for next month are to obtain spectra from other known sources to confirm that new experimental arrangement works.

\section{References:}

1. Harima, H., Ohnishi, H., Hanaoka, K., Tachibana, K., and Goto, Y., "An IR Study on the Stability of $\mathrm{Y}(\mathrm{DPM})_{3}, \mathrm{Ba}(\mathrm{DPM})_{2}$, and $\mathrm{Cu}(\mathrm{DPM})_{2}$ for UV Irradiation," Japanese Journal of Applied Physics, 30 (9A) pp. 1946-1955, September 1991.

2. Cotton, F. and Wise, J., "The Electronic Structures of Bis(B-ketoenolato)copper(II) Complexes," Journal of the American Chemical Society, 88, pp. 3451-3452, 1966.

\section{OPEN ITEMS}

UTSI: Completion of actions to insure tagging of all government property and reply to DOE/FETC that actions are completed.

The following Draft Topical Reports are awaiting approval by DOE.

"Bench Scale Evaluation of Solution Growth Based Techniques for Manufacturing HTS Wire/Tape" and "Characterization of High Temperature Superconductor Film Layers Using Raman Spectroscopy."

The Draft Quarterly Technical Progress Report for the period April - June 1999 is awaiting approval by DOE. 


\section{SUMMARY STATUS ASSESSMENT AND FORECAST}

Environmental restoration activities at the CFFF will continue and funding to cover these activities will be continued in accordance with the SETTLEMENT AGREEMENT.

Contract reporting requirements are being met on time. Future contract reporting requirements need to be reviewed and modified in accordance with the SETTLEMENT AGREEMENT. 


\section{JULY 1, 1999-SEPTEMBER 30, 1999 QUARTERLY VARIANCE REPORT}

Planned vs. Actual Expenditures

(thousands of dollars)

$\begin{array}{cr}\text { TASK } & \text { PLANNED } \\ 1 & 0.0 \\ 2 & 10.2 \\ 3 & 27.7 \\ 4 & 0.0 \\ 5 & 0.0 \\ 6 & 171.5 \\ \text { TOTALS } & 209.4\end{array}$

$\begin{array}{cr}\text { ACTUALS } & \text { VARIANCE } \\ 0.0 & 0.0 \\ 0.0 & 10.2 \\ 12.3 & 15.4 \\ 0.0 & 0.0 \\ 0.0 & 0.0 \\ 148.3 & 23.2 \\ 160.6 & 48.8\end{array}$

\section{COST ELEMENT \\ DIRECT LABOR \\ FRINGE BENEFITS \\ EQUIPMENT \\ EXPENDABLE MATERIAL \\ OUTSIDE CONTRACTS \\ TRAVEL}

TOTAL DIRECT COSTS

INDIRECT COSTS

TOTAL
100.2

21.1

0.0

12.1

4.6

4.9

142.9

66.5

209.4
83.2

19.6

0.0

1.3

2.9

2.0

109

51.6

160.6
17

1.5

0

10.8

1.7

2.9

33.9

14.9

48.8
Planned vs. Authorized Funding

Cumulative

Task

1

2

3

4

5

SUBTOTAL

6

TOTAL
PLANNED
1496.4
614.3
558.3
0.0
0.0

2669.0

3689.7

6358.7
AUTHORIZED FUNDING

2282.7

3820

6102.7 